\title{
Cardiovascular Magnetic Resonance and prognosis in cardiac amyloidosis
}

\author{
Alicia M Maceira1', Sanjay K Prasad ${ }^{2}$, Philip N Hawkins ${ }^{3}$, Michael Roughton ${ }^{4}$ \\ and Dudley J Pennell*2
}

Address: ${ }^{1}$ Cardiac Imaging Unit - ERESA. Hospital Arnau de Vilanova, Valencia, Spain, ${ }^{2}$ Cardiovascular Magnetic Resonance Unit, Royal Brompton Hospital, London, UK, ${ }^{3}$ National Amyloidosis Centre, Royal Free Hospital, London, UK and ${ }^{4}$ Medical Statistics Department, Royal Brompton Hospital, London, UK

Email: Alicia M Maceira - amaceira@eresa.com; Sanjay K Prasad - s.prasad@rbht.nhs.uk; Philip N Hawkins - phawkins@medsch.ucl.ac.uk; Michael Roughton - m.roughton@imperial.ac.uk; Dudley J Pennell* - d.pennell@ic.ac.uk

* Corresponding author

Published: 25 November 2008

Journal of Cardiovascular Magnetic Resonance 2008, 10:54 doi:10.1 186/1532-429X-10-54

This article is available from: http://www.jcmr-online.com/content/10/1/54

(C) 2008 Maceira et al; licensee BioMed Central Ltd.

This is an Open Access article distributed under the terms of the Creative Commons Attribution License (http://creativecommons.org/licenses/by/2.0), which permits unrestricted use, distribution, and reproduction in any medium, provided the original work is properly cited.
Received: 12 November 2008

Accepted: 25 November 2008

\begin{abstract}
Background: Cardiac involvement is common in amyloidosis and associated with a variably adverse outcome. We have previously shown that cardiovascular magnetic resonance (CMR) can assess deposition of amyloid protein in the myocardial interstitium. In this study we assessed the prognostic value of late gadolinium enhancement (LGE) and gadolinium kinetics in cardiac amyloidosis in a prospective longitudinal study.

Materials and methods: The pre-defined study end point was all-cause mortality. We prospectively followed a cohort of 29 patients with proven cardiac amyloidosis. All patients underwent biopsy, 2D-echocardiography and Doppler studies, ${ }^{123}$ I-SAP scintigraphy, serum NT pro BNP assay, and CMR with a $T_{1}$ mapping method and late gadolinium enhancement (LGE).

Results: Patients with were followed for a median of 623 days (IQ range 22I, 1436), during which 17 (58\%) patients died. The presence of myocardial LGE by itself was not a significant predictor of mortality. However, death was predicted by gadolinium kinetics, with the 2 minute post-gadolinium intramyocardial $\mathrm{TI}$ difference between subepicardium and subendocardium predicting mortality with $85 \%$ accuracy at a threshold value of $23 \mathrm{~ms}$ (the lower the difference the worse the prognosis). Intramyocardial TI gradient was a better predictor of survival than FLC response to chemotherapy (Kaplan Meier analysis $\mathrm{P}=0.049$ ) or diastolic function (Kaplan-Meier analysis $\mathrm{P}=\mathbf{0 . 2 0 5}$ ).
\end{abstract}

Conclusion: In cardiac amyloidosis, CMR provides unique information relating to risk of mortality based on gadolinium kinetics which reflects the severity of the cardiac amyloid burden.

\section{Background}

Amyloidosis is an uncommon condition caused by the deposition of misfolded, insoluble aggregated protein with a characteristic $\beta$-sheet structure in tissues throughout the body [1]. Cardiac involvement is frequent in sys- temic amyloidosis of immunoglobulin light chain (AL) and transthyretin (TTR) types, is associated with a poor prognosis [2], and can have therapeutic implications. Accumulation of amyloid in the myocardial interstitium [3] leads to diastolic dysfunction and restrictive cardiomy- 
opathy that progresses to overt heart failure and death [4]. Cardiac involvement is the cause of death in approximately half of patients with AL amyloidosis [5].

Cardiac amyloidosis is characterized histologically by infiltration and expansion of the interstitial space with amyloid protein, along with some associated endomyocardial fibrosis [6]. We have previously reported that cardiovascular magnetic resonance (CMR) frequently shows a characteristic pattern of global subendocardial late gadolinium enhancement (LGE) in cardiac amyloidosis that accords with the transmural histological distribution of amyloid [6]. However, there are also abnormal myocardial and blood pool gadolinium kinetics which are likely to reflect cardiac amyloid load, and therefore might relate to prognosis in these patients. We examine here the hypothesis that LGE and gadolinium kinetics might be of prognostic value in cardiac amyloidosis.

\section{Methods}

We prospectively followed our previously reported cohort of 29 patients with proven cardiac amyloidosis from the National Amyloidosis Centre of the United Kingdom [6], who were recruited and scanned between August 2002 and April 2003. The study was approved by the local Ethical Committee and written, informed consent was obtained from all patients. The amyloidosis was of TTR type in 4 patients, and monoclonal light chain (AL) type in 25 cases. The CMR methodology and baseline characteristics of these subjects have been published previously [6]. Briefly, all patients underwent biopsy (2 cardiac, 27 non-cardiac sites), 2D-echocardiography and Doppler studies, ${ }^{123}$ I-SAP scintigraphy to measure extra-cardiac amyloid burden, serum NT pro BNP assay, and CMR. CMR was performed on a 1.5T scanner (Siemens Sonata, Erlangen, Germany) with acquisition of fast imaging with steady-state free precession 2 chamber, 4 chamber and contiguous short-axis breath-hold cines $(7 \mathrm{~mm}$ slice thickness, repetition time/echo time of 3.2/1.6 ms; temporal resolution $25 \mathrm{~ms}$; retrospective gating; pixel size $2.4 \times 1.5$ $\mathrm{mm}$; flip angle $60^{\circ}$; acquisition time 18 heartbeats) for mass and volumes measurements. For LGE, a peripheral bolus injection $(0.1 \mathrm{mmol} / \mathrm{kg})$ of gadolinium-DTPA (Schering, Berlin, Germany) was given. A $T_{1}$ mapping method was developed consisting of a magnetization prepared segmented FISP cine with a $30 \mathrm{~ms}$ increment in inversion time for each frame. This was run every 2 minutes after the gadolinium bolus starting immediately after gadolinium injection and prior to late enhancement imaging, which was only started after 10 minutes. Segmentation was 13-25 lines, with triggering every 2-3 heart beats. Subsequent to this gadolinium kinetics imaging, late gadolinium enhancement images were also acquired using a segmented inversion recovery sequence (segmentation was 13 to 25 lines, with triggering every 2 to 3 heartbeats).

Echocardiography was performed on a GE Vingmed System with the use of standard techniques, as previously described [6]. In brief, left ventricular (LV) wall thickness was measured from the M-mode at the level of the chordae. Diastolic dysfunction at the time of study entry was assessed by PW Doppler of transmitral and pulmonary venous inflow velocities. These were measured in at least 3 consecutive beats and averaged for each measurement of the following: transmitral flow - peak velocity of early (E) and late (A) filling waves; E/A ratio; E-wave deceleration time; pulmonary venous flow: peak velocity of systolic, diastolic and A reversal waves. Abnormal diastolic function was classified according to standard criteria $[7,8]$, in 3 dysfunctional filling patterns: slow relaxation, pseudonormal, and restrictive.

For patients with AL amyloidosis, the haematological response to chemotherapy was categorized into no response, partial response or complete response, according to whether aberrant amyloidogenic serum free light chain (FLC) concentration had fallen $<50 \%, \geq 50 \%$ or completely following chemotherapy [9].

\section{CMR analysis}

Ventricular volumes, function, and mass were analysed as previously described and compared to age and gender matched controls [10]. LGE was assessed as present (LGE+) or absent (LGE-). For analysis of the myocardial gadolinium kinetics, 2 doughnut-shaped regions of interest were drawn, incorporating the whole subendocardium (inner third of myocardium) and the whole subepicardium (outer third of myocardium) for each frame of the mapping series in a single midventricular slice; blood pool and background were also measured. An iterative computer model was used to obtain the T1 from blood, subendocardium, and subepicardium.

\section{Event data}

The pre-defined study end point was all-cause mortality. Patients were followed-up at the National Amyloidosis Centre and events were recorded by communication with patients and/or families, their cardiologists, and general practitioners. One patient was lost to follow-up. The duration of follow-up was computed using the date of the CMR scan to the date of the end point reached. For patients who did not reach the end point, follow-up data were collected to the time of their last clinical follow-up.

\section{Statistical analysis}

For the statistical analysis, SPSS software (version 14.0, SPSS Inc, Chicago, Illinois) was used. All non-survival quantitative variables except NT proBNP were found to 
conform to normality with the Kolmogorov-Smirnov test and are therefore presented as mean $\pm \mathrm{SD}$. The NT proBNP and survival time data are presented as median $\left(25^{\text {th }}\right.$ quartile, $75^{\text {th }}$ quartile). A 2-tailed Student $t$-test was used to compare continuous variables, and the $\chi^{2}$ or Fisher's exact test was used for categorical variables. The Mann-Whitney U-test was used to compare NT proBNP between groups. A repeated-measures, mixed factorial design, 3-way ANOVA was used to analyze the change in T1 in blood, subepicardium and subendocardium with subject status (alive or dead), time after gadolinium injection, and subjects used as factors and FLC used as a covariable. Receiver operating characteristic (ROC) curves were plotted to determine the overall performance of different measurements for predicting outcome. Survival estimates and cumulative event rates were estimated using the KaplanMeier method. The log-rank test was used to compare the survival estimates for a number of factors. Cox proportional hazards analysis was not used because there were zero deaths in the most significant gadolinium group (intramyocardial T1 gradient at 2 minutes) which precludes this analysis, due to division by zero errors. Given the small number of patients, no multivariate analysis was done. A p value of $<0.05$ was considered statistically significant.

The authors had full access to the data and take responsibility for its integrity. All authors have read and agree to the manuscript as written.

\section{Results}

\section{Patient characteristics}

The baseline characteristics of this cohort have been reported previously. [6] The median duration of followup was 623 days $(221,1436)$ and during this time 17 patients $(58 \%)$ died. The median survival for those who died was $265(163,517)$ days. Table 1 shows the characteristics of the patients according to their status at followup. Among the AL amyloid patients, 3 patients in the alive group and 7 in the dead group had predominant cardiac involvement. In this group, patients with complete response to chemotherapy survived longer than those with no response $(P=0.004)$. Patients who died had smaller left ventricular $(L V ; P=0.02)$ and right ventricular $(\mathrm{RV} ; \mathrm{P}=0.045)$ stroke volume, and higher heart rate $(\mathrm{P}=$ 0.02). Patients with restrictive or pseudonormal patterns of diastolic function had a higher mortality than patients with normal or slow relaxation patterns $(P=0.04)$. No other significant differences were found according to LV and RV volumes and function (even when corrected for body surface area), age, gender, blood pressure and New York heart failure (NYHA) class. NT pro-BNP levels and LV mass did not show significant outcome differences. One patient was lost to follow up (AL systemic amyloid, no response to chemotherapy, no late gadolinium enhancement, gadolinium kinetics were not evaluated). Inclusion of this patient as dead or alive did not change the results of prediction of survival for the tested parameters. The results presented therefore do not include this patient.

\section{Late Gadolinium Enhancement and Survival}

There were $20 \mathrm{LGE}+$ patients. There were 5 deaths in the LGE- group and 12 in the LGE+ group $(P=0.31)$. Median survival was $710(115,1451)$ days for the LGE- group and $536(252,1415)$ days for the LGE+ group. Kaplan-Meier analysis showed no significant difference in survival between the 2 groups based on this parameter $(\mathrm{P}=0.36$; figure 1).

\section{Gadolinium Kinetics and Survival}

After injection, blood gadolinium clearance was faster in the patients who died, resulting in a higher blood $\mathrm{T} 1$ over time $(\mathrm{P}=0.033$, figure $2 \mathrm{a})$, although differences were small. No significant difference was found between groups in subendocardium gadolinium clearance over time $(P=0.83$. figure $2 b)$ and the difference between groups in subepicardial gadolinium clearance showed borderline significant slower gadolinium clearance in the patients who died $(\mathrm{P}=0.054$; figure $2 \mathrm{c})$.

The intramyocardial $\mathrm{T} 1$ gradient (subepicardium $\mathrm{T} 1$ minus subendocardium T1), for which higher values indicate less gadolinium in the epicardium, showed significant differences of greater magnitude with respect to outcome. Patients who survived had a higher intramyocardial T1 gradient than the patients who died (figure 3a; $\mathrm{P}=0.005)$. ROC analysis showed that an intramyocardial T1 gradient of $23 \mathrm{~ms}$ at 2 minutes yielded an optimal $85 \%$ accuracy for predicting survival $(100 \%$ sensitivity, $66 \%$ specificity) (table 2). Kaplan-Meier curves showed significant differences in survival at the $23 \mathrm{~ms}$ threshold (figure $3 b, P=0.005)$.

Surviving patients also had a higher subepicardial minus blood T1 difference, again reflecting lower epicardial gadolinium uptake (figure $4 \mathrm{a} ; \mathrm{P}<0.001$ ). ROC curves showed that a subepicardium-blood T1 difference of 80 ms at 4 minutes yielded 90\% accuracy for mortality (91\% sensitivity, $88 \%$ specificity; table 2). Kaplan-Meier curves showed significant differences in mortality at the $80 \mathrm{~ms}$ threshold (figure $4 \mathrm{~b} ; \mathrm{P}=0.002$ ). Surviving patients also showed a higher subendocardial-blood $\mathrm{T} 1$ difference (figure $5 ; \mathrm{P}=0.031$ ) but ROC results showed that this parameter did not predict survival.

Due to the sample size, no multivariable analysis was done and Kaplan-Meier curves were used instead to compare survival with respect to several parameters. Since both the pattern of diastolic function and FLC response to 
Table I: Characteristics of patients at baseline according to outcome. Table shows number or mean \pm SD, except NT pro-BNP which is median ( $25^{\text {th }}$ centile, $7^{\text {th }}$ centile)

\begin{tabular}{|c|c|c|c|}
\hline & Alive & Dead & $P$ \\
\hline $\mathrm{N}$ & 11 & 17 & \\
\hline Age, years & $58 \pm 11$ & $58 \pm 10$ & 0.99 \\
\hline Male & 5 & 9 & 0.57 \\
\hline \multicolumn{4}{|l|}{ Type of amyloidosis } \\
\hline $\mathrm{AL}$ & 10 & 14 & \\
\hline TTR & I & 3 & 0.67 \\
\hline NT pro-BNP (pMol/L) $[\mathrm{N}<20]$ & $462(181,746)$ & $591(456,1176)$ & 0.11 \\
\hline \multicolumn{4}{|l|}{ FLC } \\
\hline No response & I & 10 & \\
\hline Partial response & 5 & 4 & \\
\hline Complete response & 4 & 0 & 0.004 \\
\hline Systolic BP, $\mathrm{mmHg}$ & $120 \pm 10$ & $113 \pm 5$ & 0.29 \\
\hline Diastolic BP, $\mathrm{mmHg}$ & $70 \pm 3$ & $65 \pm 4$ & 0.10 \\
\hline Heart rate, beats/min & $75 \pm 13$ & $89 \pm 12$ & 0.02 \\
\hline \multicolumn{4}{|l|}{ NYHA functional class } \\
\hline I & 6 & 8 & \\
\hline ॥ & 4 & 7 & \\
\hline III & 0 & 2 & \\
\hline IV & I & 0 & 0.67 \\
\hline \multicolumn{4}{|l|}{ Diastolic function pattern } \\
\hline Normal & 3 & 0 & \\
\hline Slow relaxation & 5 & 7 & \\
\hline Pseudonormal & I & 2 & \\
\hline Restrictive & 2 & 8 & 0.04 \\
\hline \multicolumn{4}{|l|}{ CMR dimensions and function } \\
\hline LV EDV, mL & $108 \pm 30$ & $95 \pm 23$ & 0.20 \\
\hline LV ESV, mL & $39 \pm 15$ & $4 I \pm 2 I$ & 0.73 \\
\hline LV SV, mL & $70 \pm 21$ & $54 \pm 13$ & 0.02 \\
\hline LV EF, \% & $63 \pm 10$ & $58 \pm 12$ & 0.19 \\
\hline LV mass, $g$ & $204 \pm 79$ & $201 \pm 54$ & 0.93 \\
\hline RV EDV, mL & $111 \pm 36$ & $95 \pm 24$ & 0.18 \\
\hline RV ESV, $\mathrm{mL}$ & $43 \pm 20$ & $42 \pm 21$ & 0.88 \\
\hline $\mathrm{RV} \mathrm{SV}, \mathrm{mL}$ & $68 \pm 20$ & $54 \pm 15$ & 0.045 \\
\hline RVEF, \% & $61 \pm 8$ & $58 \pm 14$ & 0.43 \\
\hline $\mathrm{RV}$ mass, $\mathrm{g}$ & $72 \pm 21$ & $68 \pm 20$ & 0.64 \\
\hline \multicolumn{4}{|l|}{ AV plane descent, $\mathrm{mm}$} \\
\hline LV septum & $8 \pm 3$ & $6 \pm 5$ & 0.36 \\
\hline LV lateral wall & $9 \pm 4$ & $7 \pm 4$ & 0.28 \\
\hline RV septum & $9 \pm 4$ & $9 \pm 3$ & 0.60 \\
\hline RV lateral wall & $15 \pm 7$ & $12 \pm 5$ & 0.25 \\
\hline
\end{tabular}

chemotherapy have been considered significant predictors of mortality in this condition, Kaplan-Meier curves were produced in order to compare differences in survival according to these two variables (figure 6). Patients with partial or complete response to chemotherapy showed a better survival than those with no response, though the degree of significance was not as good as that of gadolinium kinetics parameters $(P=0.049)$. Finally, no significant differences were found in survival between patients with normal/slow relaxation compared to pseudonormal/ restrictive diastolic pattern.

\section{Discussion}

Accumulation of amyloid in the myocardial interstitium results in late gadolinium enhancement (LGE), often with a predominant diffuse, global and subendocardial distribution that matches the distribution of amyloid on histology $[6,11,12]$, although other more focal patterns have also been reported [13]. This is associated with substantial alterations in gadolinium kinetics, with faster washout of gadolinium from blood and myocardium than normal [6]. This study extends the value of these diagnostic findings, and shows for the first time that CMR may yield useful prognostic information in patients with cardiac amyloidosis. The presence alone of LGE did not correlate significantly with survival, although the sample size of this study was relatively small, but gadolinium kinetics were associated with significant survival differences according to several derived parameters. A likely explanation for the discrepancy between LGE and the kinetics 




Figure I

Survival curve according to late gadolinium enhancement (LGE). The figure shows the Kaplan Meier curve of survival according to the presence or absence of late gadolinium enhancement (LGE). No differences in survival were seen with respect to this parameter.

with outcome is the superior discrimination by gadolinium kinetics for the severity and transmurality of the myocardial amyloid burden. This is illustrated by the results of the intramyocardial T1 difference parameter. Previous work showed that the usual pattern of amyloid protein deposition in the myocardium is predominantly subendocardial with variable transmural extension, [6] under which circumstances the subepicardial (low amyloid, low gadolinium, high T1) minus subendocardial T1 (higher amyloid, higher gadolinium, lower T1) difference would be expected to be high. With greater myocardial amyloid deposition, including greater deposition in the subepicardium, the transmural difference in amyloid diminishes, leading to a reduction in the intramural T1 gradient. This is supported by the other significantly predictive derived parameter in which myocardial $\mathrm{T} 1$ is compared with blood T1; the subepicardial minus blood T1 difference also predicted survival, with lower values associated with death. Usually blood contains more gadolinium (lower T1) because of a substantially greater volume of distribution, and therefore a large positive T1 gradient between subepicardium and blood exists. This gradient would be reduced if greater subepicardial amyloid (lower T1) is present. Of interest is that the subendocardial minus blood T1 difference did not show differences in survival. It therefore appears that deposition in the subepicardium may be the principal statistical driver for prediction of mortality. The explanation for this finding can be that
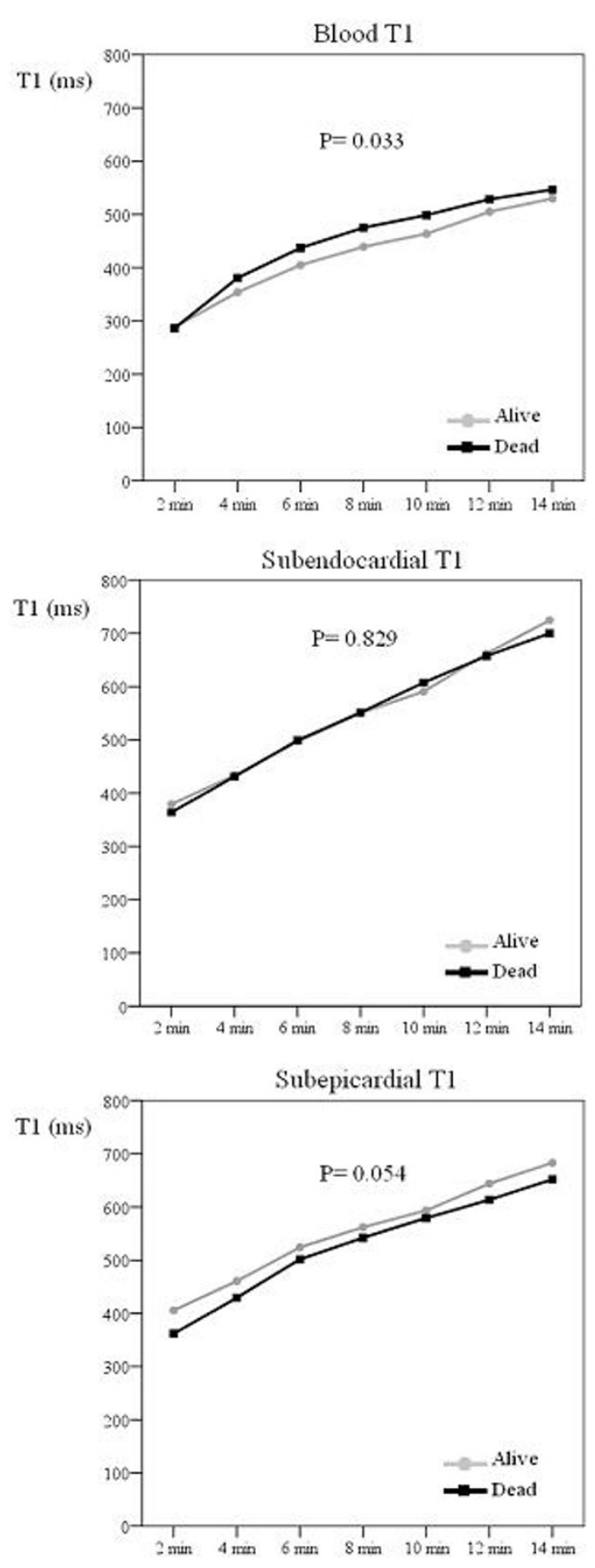

Figure 2

Differences in TI after gadolinium injection between survivors and patients who died. The figure shows the differences in $\mathrm{Tl}$ of blood, subendocardium and subepicardium with time after gadolinium injection between survivors and patients who died on follow-up. Patients who died on follow up showed a higher blood TI after gadolinium injection. 

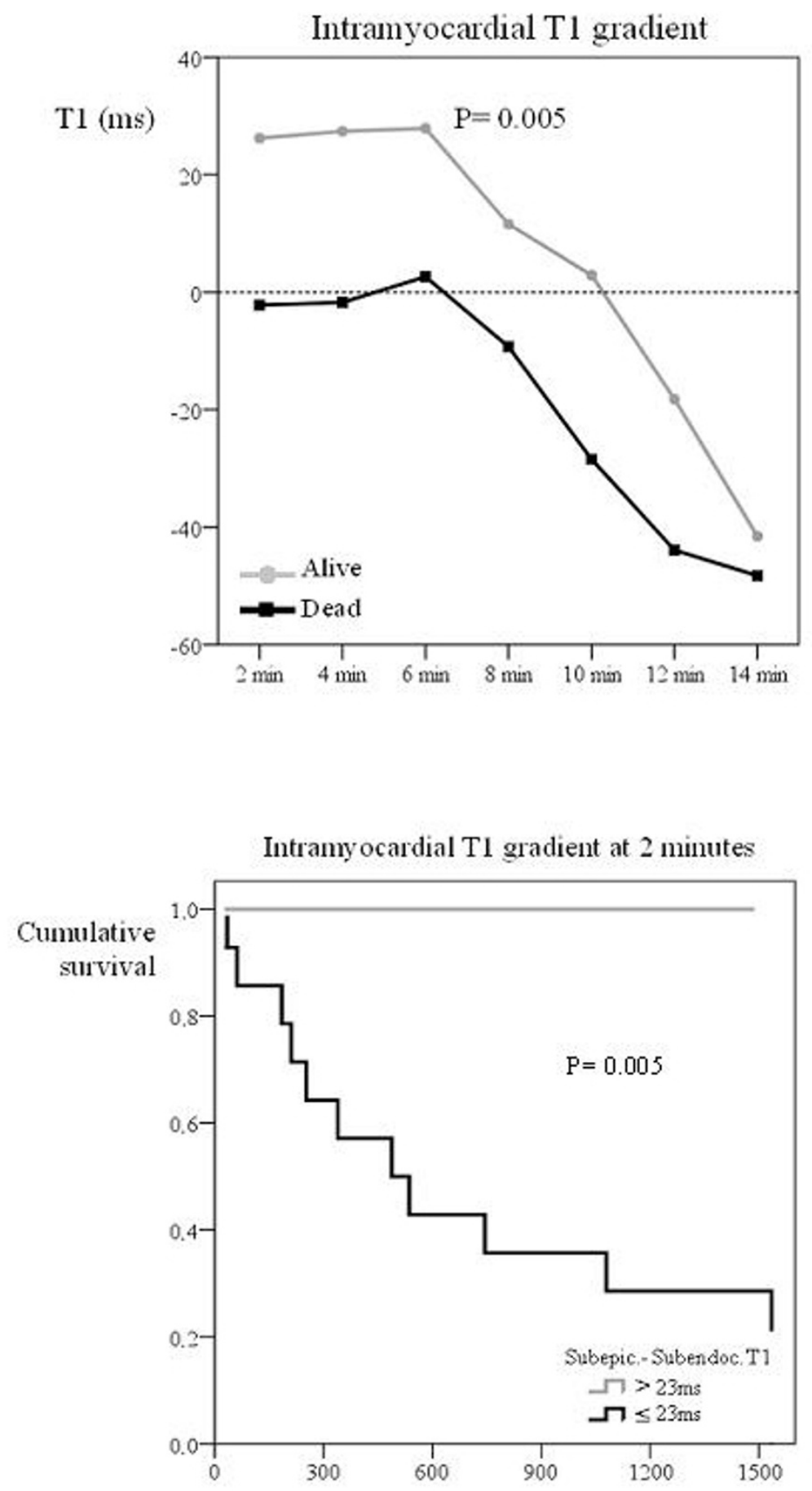

Figure 3

Top: Intramyocardial TI difference in survivors and patients who died. Bottom: Survival curve according to intramyocardial TI difference. The top graph shows the intramyocardial TI difference (subepicardium - subendocardium) with time after gadolinium injection in survivors and patients who died. Survivors showed a significantly higher intramyocardial TI difference after gadolinium injection. The bottom image shows the Kaplan Meier curve of survival according to intramyocardial TI difference set a threshold value of 23 ms. Patients with an intramyocardial TI difference above 23 ms had increased survival. 

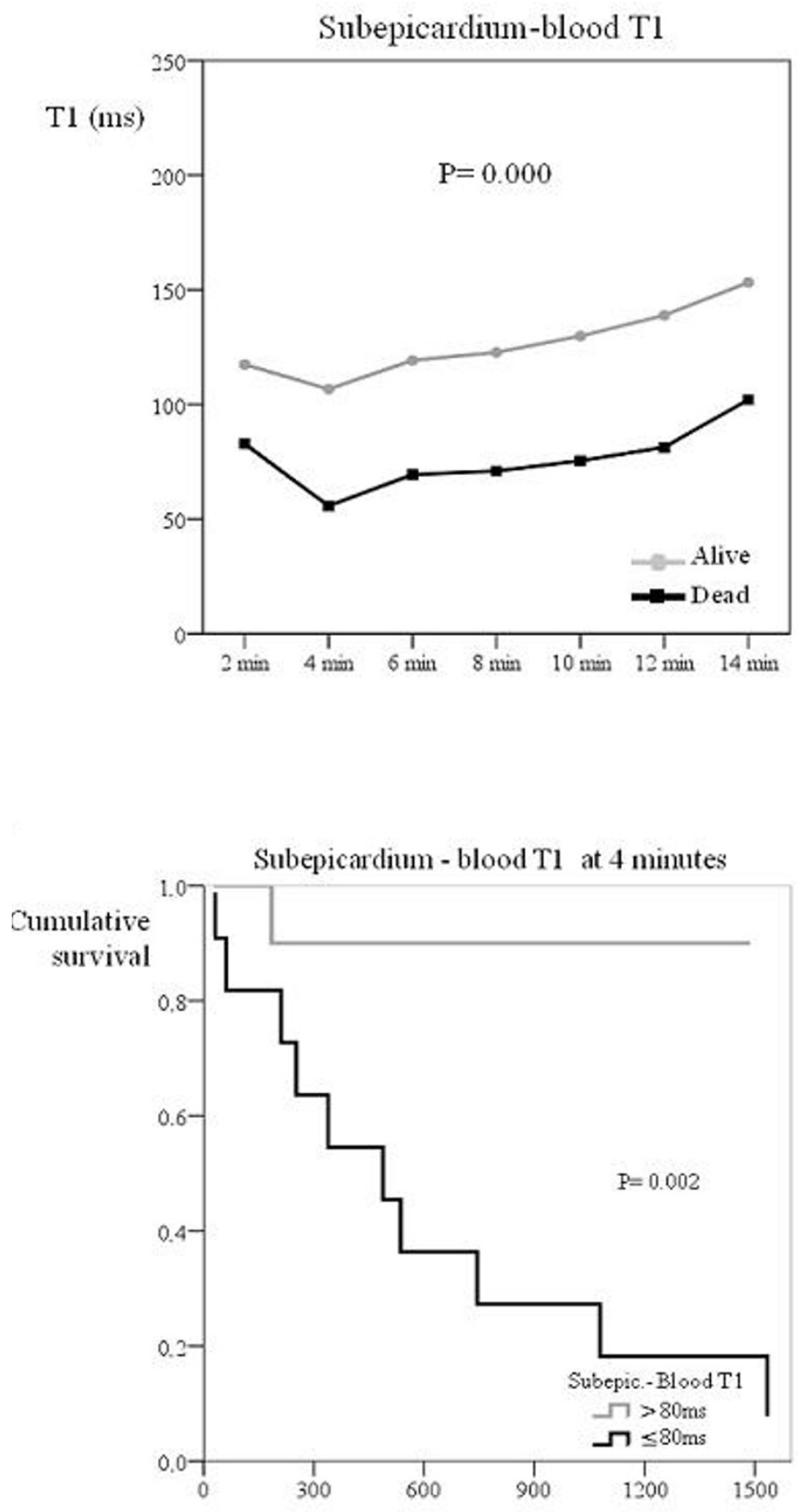

Figure 4

Top: Subepicardium to blood TI difference in survivors and patients who died. Bottom: Survival curve according to this TI difference. The top graph shows the subepicardium to blood TI difference with time after gadolinium injection in survivors and patients who died. Survivors showed a significantly higher subepicardium to blood TI difference after gadolinium injection. The bottom figure shows the Kaplan Meier curve of survival according to subepicardium to blood TI difference set at a threshold value of 80 ms. Patients with a subepicardium to blood TI difference above 80 ms had a better survival. 



\section{Figure 5}

Top: Subendocardium to blood TI difference in survivors and those who died. Bottom: Survival curve according to this TI difference. The top graph shows the subendocardium to blood TI difference with time after gadolinium injection in survivors and patients who died. Survivors showed a significantly higher subendocardium to blood TI difference after gadolinium injection. The bottom figure shows the Kaplan Meier curve of survival according to subendocardium to blood TI difference set a threshold value of $68 \mathrm{~ms}$. No significant differences in survival were seen for this parameter. 

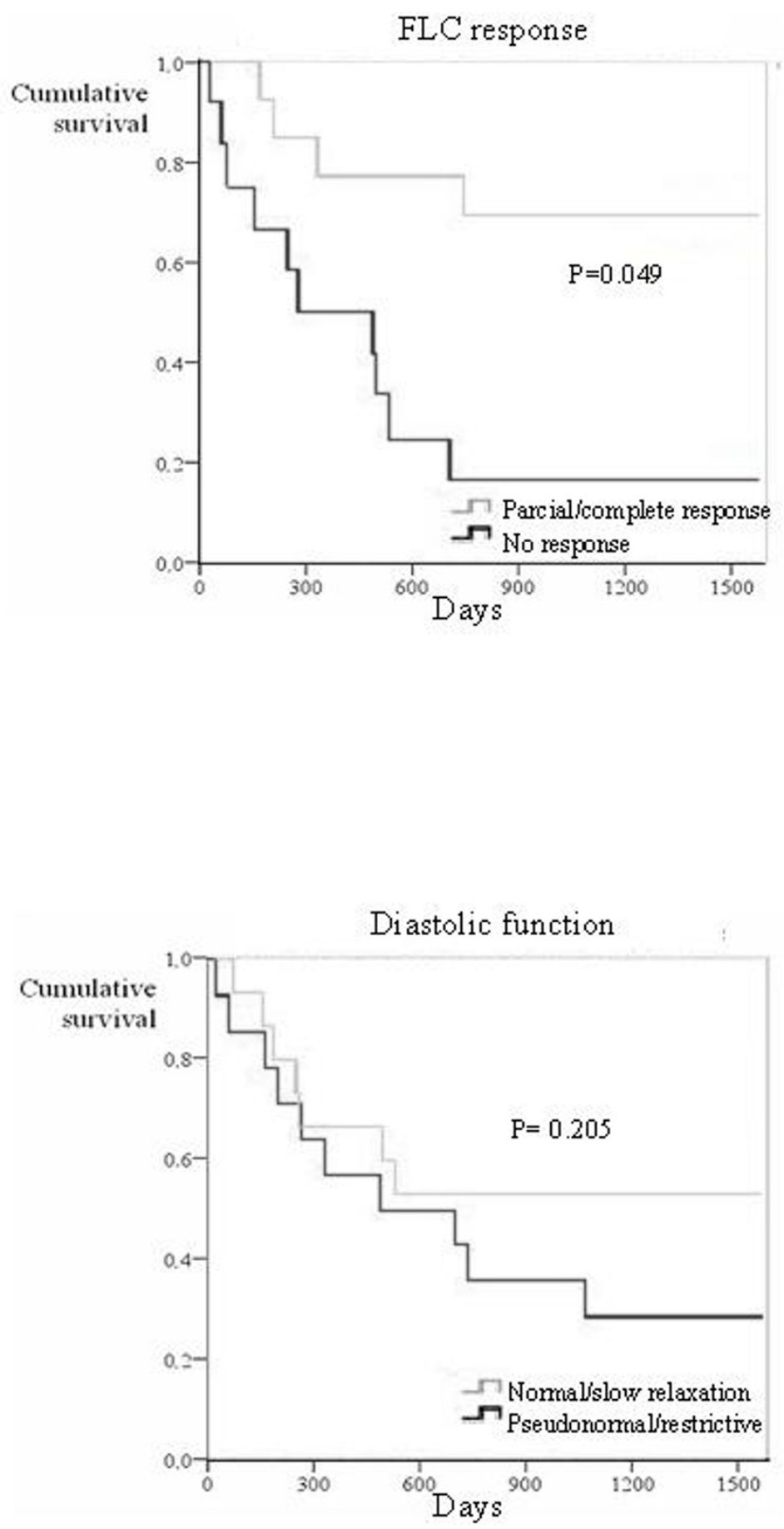

\section{Figure 6}

Top: Survival curve according to FLC response. Bottom: Survival curve according to diastolic function. The top graph shows the Kaplan Meier curve of survival according to free light chain response to chemotherapy. Patients with partial/ complete response had better survival. The bottom image shows the Kaplan Meier curve of survival according to diastolic function. The discrimination of survivors from non-survivors was superior for gadolinium kinetics (figure 3). 
Table 2: Diagnostic accuracy of gadolinium kinetics parameters for death. Diagnostic accuracy of gadolinium kinetics parameters for using receiver operating characteristic curve analysis (AUC = area under curve).

\begin{tabular}{lllllll}
\hline & AUC & $P$ & Cut-off value & Sens (\%) & Spec (\%) & Accuracy (\%) \\
\hline Subepicardium TI (2 min) & 0.784 & 0.039 & 386 & 82 & 75 & 75 \\
Intramyocardial TI gradient (2 min) & 0.833 & 0.012 & 23 & 100 & 66 & 85 \\
Subepicardial -blood TI (4 min) & 0.875 & 0.006 & 80 & 91 & 88 & 90 \\
\hline
\end{tabular}

subendocardial amyloid deposition is usual, and it is not until the burden of amyloid deposition increases that the subepicardium has substantial involvement. Thus it is possible that subepicardial involvement partially reflects the total myocardial amyloid burden. However, the direct predictive value for death of subepicardial T1 was less than the derived measures already mentioned $(\mathrm{P}=0.039$; table 2; Kaplan Meier curves not significant), and therefore the derived measures are more important.

Cardiac involvement in amyloidosis is a major risk factor for adverse outcome [14]. Previously proposed associations with poor prognosis in cardiac amyloidosis include reduced ejection fraction, low ECG voltages, increased left ventricular wall thickness on echo, and the type of amyloidosis (with worse prognosis in AL compared with TTR type) [15]. In addition, the degree of diastolic dysfunction [16] and suppression of amyloidogenic serum light chains by chemotherapy, and lower baseline values and greater reductions in NT-proBNP have been associated with improved outcome $[9,17]$. Our data now suggest that gadolinium kinetics may be even more predictive than these measures. The value of the CMR measurements may in part be due to the fact that cardiac amyloid burden cannot be measured satisfactorily by other techniques, and therefore CMR may offer a fundamental new window into the cardiac pathology in this disease.

Treatment options in amyloidosis have been expanding [18], and some novel pharmaceuticals have lately shown considerable promise $[19,20]$. Patients with a particular poor prognosis may benefit from sequential heart and autologous stem cell transplantation [21-23]. Recognition that T1 mapping in cardiac amyloidosis may be significantly more predictive of poor prognosis than the other currently used measures may be beneficial in the clinical management of AL patients by identifying those in whom early use of more intensive chemotherapy might be justified with the aim of achieving more rapid and complete remission of their underling clonal plasma cell disease. It is of interest that there is precedent for the burden of myocardial disease as assessed by CMR being predictive of outcome in hypertrophic, dilated and siderotic cardiomyopathies [24-26], with the severity of fibrosis $[24,25,27]$ and iron loading [28].
A number of the gadolinium kinetics parameters in this study were significantly associated with mortality, but the one with greatest discriminatory value was the intra-myocardial T1 gradient after gadolinium injection, with 95\% accuracy at a threshold value of $23 \mathrm{~ms}$ (Kaplan Meier analysis $\mathrm{P}=0.002$ ). Although further experience and reproduction of these results by other centres is necessary, the technique is in principle straightforward and could be implemented on most 1.5T scanners. Optimisation of the acquisition sequence and analysis software would also be valuable.

\section{Study limitations}

Patient numbers were relatively small but cardiac amyloidosis is a rare disease. The diagnosis of cardiac amyloidosis did not routinely include endocardial biopsy, in keeping with standard clinical practice in the UK National Amyloid Centre and international consensus guidelines on diagnosis and organ involvement in amyloidosis [29]. The measurement technique for $\mathrm{T} 1$ includes assumptions about the relaxivity of gadolinium-DTPA being the same in blood and myocardium. Due to the small sample size, no multivariable analysis was carried out.

\section{Conclusion}

This study shows that gadolinium kinetics assessed by $\mathrm{T} 1$ relaxation CMR is useful in the prognostic assessment of cardiac amyloidosis and this could have utility in assessing patients for treatments, and in their follow-up.

\section{Competing interests}

This study was supported by CORDA and The British Heart Foundation. Research support was also received from Siemens Medical Solutions. The authors declare that they have no competing interests.

\section{Authors' contributions}

AMM conceived the study, carried out the CMR studies, obtained and analysed the data and drafted the manuscript. SKP helped to analyse the data and draft the manuscript. PNH helped with conception and design of the study and helped to draft the manuscript. MR participated in the design of the study and the statistical analysis. DJP conceived the study, participated in its design and coordination and helped to draft the manuscript. All authors read and approved the final manuscript. 


\section{References}

I. Falk RH, Comenzo RL, Skinner M: The systemic amyloidoses. $N$ Engl J Med 1997, 337:898-909.

2. Kyle RA, Greipp PR, O'Fallon WM: Primary systemic amyloidosis: multivariate analysis for prognostic factors in 168 cases. Blood 1986, 68:220-4.

3. Arbustini E, Gavazzi A, Merlini G: Fibril-forming proteins: the amyloidosis: new hopes for a disease that cardiologists must know. Ital Heart J Suppl 2002, 3(6):590-597.

4. Nihoyannopoulos P: Amyloid heart disease. Current Opin Cardiol | 987, 2:37|-6.

5. Falk RH, Skinner M: The systemic amyloidoses: an overview. Adv Intern Med 2000, 45: I07-I 37.

6. Maceira AM, Joshi J, Prasad SK, Moon JCC, Perugini E, Harding I, Sheppard MN, Poole-Wilson PA, Hawkins PN, Pennell D: Cardiovascular magnetic resonance in cardiac amyloidosis. Circulation 2005, I I I: | 95-202.

7. Klein AL, Hatle LK, Burstow DJ, Seward JB, Kyle RA, Bailey KR, Luscher TF, Gertz MA, Tajik AJ: Doppler characterization of left ventricular diastolic function in cardiac amyloidosis. J Am Coll Cardiol 1989, 13:1017-1026.

8. Moyssakis I, Tripdskiadis F, Rallidis L, Hawkins P, Kyriakidis M, Nihoyannopoulos P: Echocardiographic features of primary, secondary and familial amyloidosis. Eur J Clin Invest 1999, 29:484-489.

9. Lachmann HJ, Gallimore R, Gillmore JD, Carr-Smith HD, Bradwell AR, Pepys MB, Hawkins PN: Outcome in systemic AL amyloidosis in relation to changes in concentration of circulating free immunoglobulin light chains following chemotherapy. $\mathrm{Br} J$ Haematol 2003, I 22:78-84.

10. Maceira AM, Prasad SK, Khan M, Pennell DJ: Normalized left ventricular systolic and diastolic function by steady state free precession cardiovascular magnetic resonance. J Cardiovasc Magn Reson 2006, 8:417-26.

II. Sueyoshi E, Sakamoto I, Okimoto T, Hayashi K, Tanaka K, Toda G: Cardiac amyloidosis: typical imaging findings and diffuse myocardial damage demonstrated by delayed contrastenhanced MRI. Cardiovasc Intervent Radiol 2006, 29:710-2.

12. Cheng AS, Banning AP, Mitchell AR, Neubauer S, Selvanayagam JB: Cardiac changes in systemic amyloidosis: visualisation by magnetic resonance imaging. Int J Cardiol 2006, I I 3:E2 I-3.

13. Perugini E, Rapezzi C, Piva T, Leone O, Bacchi-Reggiani L, Riva L, Salvi F, Lovato L, Branzi A, Fattori R: Non-invasive evaluation of the myocardial substrate of cardiac amyloidosis by gadolinium cardiac magnetic resonance. Heart 2006, 92:343-9.

14. Cacoub P, Axler O, De Zuttere D, Hausfater P, Amoura Z, Walter S, Wechsler B, Godeau P, Piette JC: Amyloidosis and cardiac involvement. Ann Med Interne (Paris) 2000, I 5 I (8):6 I I-6I 7.

15. Kristen AV, Perz JB, Schonland SO, Hegenbart U, Schnabel PA, Kristen JH, Goldschmidt H, Katus HA, Dengler TJ: Non-invasive predictors of survival in cardiac amyloidosis. Eur J Heart Fail 2007, 9:6I7-24.

16. Klein AL, Hatle LK, Taliercio CP, Oh JK, Kyle RA, Gertz MA, Bailey $K R$, Seward JB, Tajik AJ: Prognostic significance of Doppler measures of diastolic function in cardiac amyloidosis. A Doppler echocardiography study. Circulation I99I, 83:808-I6.

17. Palladini G, Lavatelli F, Russo P, Perlini S, Perfetti V, Bosoni T, Obici L, Bradwell AR, D'Eril GM, Fogari R, Moratti R, Merlini G: Circulating amyloidogenic free light chains and serum $\mathbf{N}$-terminal natriuretic peptide type B decrease simultaneously in association with improvement of survival in AL. Blood 2006, 1 07:3854-8.

18. Kholova I, Kautzner J: Current treatment in cardiac amyloidosis. Curr Treat Options Cardiovasc Med 2006, 8:468-73.

19. Pepys MB, Herbert J, Hutchinson WL, Tennent GA, Lachmann HJ, Gallimore JR, Lovat LB, Bartfai T, Alanine A, Hertel C, Hoffmann T, Jakob-Roetne R, Norcross RD, Kemp JA, Yamamura K, Suzuki M, Taylor GW, Murray S, Thompson D, Purvis A, Kolstoe S, Wood SP, Hawkins PN: Targeted pharmacological depletion of serum amyloid $\mathbf{P}$ component for treatment of human amyloidosis. Nature 2002, 41 7:254-9.

20. Dember LM, Hawkins PN, Hazenberg BP, Gorevic PD, Merlini G, Butrimiene I, Livneh A, Lesnyak O, Puechal X, Lachmann HJ, Obici L, Balshaw R, Garceau D, Hauck W, Skinner M, Eprodisate for AA Amyloidosis Trial Group: Eprodisate for the treatment of renal disease in AA amyloidosis. N Engl J Med 2007, 356:2349-60.
21. Gillmore JD, Goodman HJ, Lachmann HJ, Offer M, Wechalekar AD, Joshi J, Pepys MB, Hawkins PN: Sequential heart and autologous stem cell transplantation for systemic AL amyloidosis. Blood 2006, I07:I227-9.

22. Maurer MS, Raina A, Hesdorffer C, Bijou R, Colombo P, Deng M, Drusin R, Haythe J, Horn E, Lee SH, Marboe C, Naka Y, Schulman L, Scully B, Shapiro P, Prager K, Radhakrishnan J, Restaino S, Mancini D: Cardiac transplantation using extended-donor criteria organs for systemic amyloidosis complicated by heart failure. Transplantation 2007, 83:539-45.

23. Shah KB, Inoue $Y$, Mehra MR: Amyloidosis and the heart: a comprehensive review. Arch Intern Med 2006, I 66: I805-I3.

24. Moon JC, McKenna WJ, McCrohon JA, Elliott PM, Smith GC, Pennell DJ: Toward clinical risk assessment in hypertrophic cardiomyopathy with gadolinium cardiovascular magnetic resonance. J Am Coll Cardiol 2003, 4 I: I56I-7.

25. Assomull RG, Prasad SK, Lyne J, Smith GC, Burman ED, Khan M, Sheppard MN, Poole-Wilson PA, Pennell DJ: Cardiovascular magnetic resonance, fibrosis, and prognosis in dilated cardiomyopathy. J Am Coll Cardiol 2006, 48: 1977-85.

26. Tanner MA, Galanello R, Dessi C, Westwood MA, Smith GC, Nair SV, Anderson LJ, Walker JM, Pennell DJ: Myocardial iron loading in patients with thalassemia major on deferoxamine chelation. J Cardiovasc Magn Reson 2006, 8:543-7.

27. Moon JC, Sheppard M, Reed E, Lee P, Elliott PM, Pennell DJ: The histological basis of late gadolinium enhancement cardiovascular magnetic resonance in a patient with Anderson-Fabry disease. J Cardiovasc Magn Reson 2006, 8:479-82.

28. Anderson LJ, Holden S, Davies B, Prescott E, Charrier C, Bunce NH, Firmin DN, Porter JB, Wonke B, Walker JM, Pennell DJ: Cardiovascular T2* (T2 star) magnetic resonance for the early diagnosis of myocardial iron overload. Eur Heart J 200 I, 22:2 I 7I-9.

29. Gertz MA, Comenzo R, Falk RH, Fermand JP, Hazenberg BP, Hawkins PN, Merlini G, Moreau P, Ronco P, Sanchorawala V, Sezer O, Solomon A, Grateau G: Definition of organ involvement and treatment response in immunoglobulin light chain amyloidosis (AL): a consensus opinion from the IOth International Symposium on Amyloid and Amyloidosis, Tours, France, 18-22 April 2004. Am J Hematol 2005, 79:319-28.

Publish with Biomed Central and every scientist can read your work free of charge

"BioMed Central will be the most significant development for disseminating the results of biomedical research in our lifetime. "

Sir Paul Nurse, Cancer Research UK

Your research papers will be:

- available free of charge to the entire biomedical community

- peer reviewed and published immediately upon acceptance

- cited in PubMed and archived on PubMed Central

- yours - you keep the copyright 